\section{A HOSPITAL BASED CROSS-SECTIONAL STUDY OF EPIDEMIOLOGICAL TREND OF COVID-19 AMONG ARMY PERSONNEL AND THEIR DEPENDANTS ADMITTED IN A COVID CARE HOSPITAL}

\author{
RAHUL NAYYAR ${ }^{\mathrm{a} 1}$, LAXMIKANT CHOUDHARY ${ }^{\mathrm{b}}$, TANVI MAHAJAN ${ }^{\mathrm{c}}$, ARINDAM \\ CHATTERJEE ${ }^{\mathrm{d}}$ AND BIPUL KUMAR SINGH
}

\author{
${ }^{\text {ae }}$ Department of Hospital Administration, Armed Forces Medical College, Pune, Maharashtra, India \\ ${ }^{b}$ Department of Community Medicine, Armed Forces Medical College, Pune, Maharashtra, India \\ ${ }^{c}$ Master in Health Administration, Tata Institute of Social Sciences, Mumbai, Maharashtra, India \\ ${ }^{\mathrm{d} C}$ Commandant, Army Institute of Cardiothoracic Sciences, Pune, Maharashtra, India
}

\begin{abstract}
Novel corona virus SARS-CoV-2 has caused 1638870 cases and 35747 total deaths in India till July 20. Maharashtra has reported the highest number of cases in India with case fatality rate of 3.4\%. Pune is second city after Mumbai to reach 1000 cases within 47 days. Pune has reported 1,13,004 confirmed cases with 2,728 deaths. To obtain data of various sociodemographic and epidemiological parameters in respect of army personnel and their dependants and to compare them with national figures. All laboratory confirmed COVID-19 cases (male, female of all age groups) were included in this study and the epidemiological data was prospectively collected. The current study was a hospital-based cross-sectional descriptive study of epidemiological features of COVID-19 positive patients admitted between 30 Mar to 01 Aug 20. Males were affected more in comparison to females. Majority of patients were symptomatic with fever and other symptoms like cough and sore throat as chief complaints. Most common co-morbidities identified were hypertension, cardiovascular and cerebrovascular conditions and diabetes. Case fatality rate (CFR) of patients admitted with COVID-19 is quite high as compared to the national average figure. Death rate among patients with multiple comorbidities are quite high as compared to the patients admitted with single comorbidity.
\end{abstract}

KEYWORDS: COVID-19, Epidemiology, Covid Care Hospital

The current pandemic of COVID-19, caused by a novel corona virus SARS-CoV-2 was first reported from Wuhan, (China) in Dec 19. After shoddily affecting China in terms of mortality and morbidity, it has caused 17106007 total cases and 668910 total deaths globally till $31^{\text {st }}$ Jul 20, affecting almost all the countries and territories of the world (WHO situation report 193 dated 31 st Jul 20). It was declared as Public Health Emergency of International Concern (PHEIC) on 30 Jan 20 and Pandemic on 11 Mar 20 by WHO (Wang $\mathrm{C}$ et al). The first case of COVID-19 reported in India on 30 $0^{\text {th }}$ Jan 2020 In Kerala and first death in Karnataka on $12^{\text {th }}$ Mar 2020. India is among one of badly affected countries where number of cases and deaths are abruptly increasing day by day, as of now there are 1638870 notified cases and 35747 deaths. (MoHFW website dated $31^{\text {st }}$ Jul 20).

The typical symptoms of COVID-19 disease are fever, sore throat, fatigue, cough or dyspnoea however some atypical symptoms have also been notified in this disease. It spreads the same way other coronaviruses do, mainly through person-to-person contact by respiratory droplets.

Maharashtra has reported the highest number of cases in India with 5,15,332 total cases and 17,757 total deaths as on $09^{\text {th }}$ Aug with a case fatality rate of $3.4 \%$. Pune is the second city in the Maharashtra state after Mumbai to reach the patient figure of 1000. It took 47 days for Pune to cross 1000 cases since it reports its first two cases on March 9, 2020 Pune has reported 1,13,004 confirmed cases with 2,728 deaths.

\section{MATERIALS AND METHODS}

Aims and objective of the study was to obtain data of various socio-demographic and epidemiological parameters in respect of army personnel and their dependants compare them with national figures. Army Institutes of Cardiothoracic Sciences, AICTS (ex MH CTC) is a tertiary care hospital in Pune and has been designated as dedicated COVID hospital for isolation and management of laboratory confirmed cases of serving defence personnel and their dependants, ex-serviceman

${ }^{1}$ Corresponding author 
and their dependants and few civilian patients getting admitted to this hospital after special request and further approval of commandant of this hospital. This centre started admitting the patients of COVID-19 from March 30, 2020. Results and conclusions of this study will help out our army fraternity, policy and guidelines makers to take lesions, formulate SOPs in respect of infrastructure, manpower required, modification and augmentations of military hospitals in context of such kind of pandemics and in many other sections.

All laboratory confirmed COVID-19 cases (male, female of all age groups) were included in this study and the epidemiological data was prospectively collected by person-to-person interview and interview with their relatives with a predesigned Performa included socio-demographic data, duration of stay, outcome etc. Outcome of patient was recorded as recovery and discharge, still admitted and death.

The current study was a hospital-based crosssectional descriptive study of epidemiological features of COVID-19 positive patients who presented themselves to this centre during the outbreak from 30 March 20 to 01 Aug 2020.

To conduct this study permission was taken from the head of the institution as well as written informed consent was taken from each of the patients separately. All the information were collected in excel sheets and later analysed using SPSS version 20. Ethical approval was taken from Institutional Ethics Committee (IEC).

After collection, compilation, summarization final analysis of data was done using SPSS version 20. Descriptive statistics, Chi-square test were done, significance of test decided at $p$ value 0.05 .

\section{RESULTS}

A total of 836 patients were included in the study since admission of first case on 30 Mar 20 till $31^{\text {st }}$ July. Mean age of the patients was 43.94 years and range was 02 months to 90 years. Demographic profile is shown in table 1 .

Majority of patients $(68.7 \%)$ were referred from Command hospital Pune, rest from MH Khirkee and MH Khadakwasla. It was observed that more than $2 / 3 \mathrm{rd}$ of the patients admitted were symptomatic, out of which almost half of the patients presented with fever as well as other symptoms. Nearly $30 \%$ of the infected patients had associated co-morbid conditions. Clinical profiles of the patients are shown in Table 2.

Figure 1 shows the month-wise trend of admissions, discharge and deaths. A steep surge in the number of admissions in the month of July is clearly evident.

Out of 836 total patients, 33 patients in this hospital died due to COVID-19 with case fatality rate of $3.9 \%$, in which 03 patients were brought in dead. 59.6\% patients recovered and were discharged and rest were still admitted in the hospital.

When we analyzed deceased persons we found that out of 33, 25 (75.8\%) deceased were above 60 years of age group, no death was reported in 0-14 years age group. Ratio of Deaths in males and females was approx. $3: 1$.

Bi-variate analysis of co morbidities and outcome shows that out of (249) patients with comorbidities $9.2 \%$ patients died and in patients without comorbidities (587) only $1.2 \%$ died.

Out of total patients with co-morbid conditions $(n=249), 126$ patients presented with single co-morbidity, of which $5(6.3 \%)$ died and 123 patients with multiple comorbidities, of which 18 (22.14\%) died.

When we analyzed about various comorbidities among the admitted patients we found that Hypertension was most common comorbidity followed by Diabetes Mellitus. Immunosurvellance was the least common comorbidity.

103 patients were admitted in ICU, of which one-third patients died, one-third were still admitted and remaining patients recovered and discharged. Among those admitted in ICU ( $\mathrm{N}=103), 70$ patients presented with co morbid conditions, of which $37.1 \%$ died, and 33 patients were without any co-morbidities, of which only $12.1 \%$ patients died. Among patients admitted in ICU, 34 patients required mechanical ventilation.

Bi-variate analysis of co-morbidity and symptoms show that out of 249 patients with comorbidities, $88.0 \%$ patients shows symptoms but out of 587 patients without co-morbidities, only $79.2 \%$ shows symptoms. 
Table 1: Showing Demographic Profile of the Patients

\begin{tabular}{|c|c|c|}
\hline S. no. & Characteristics & Number (Percentage) \\
\hline \multirow{3}{*}{1.} & Sex & $575(68.8 \%)$ \\
& Male & $261(31.2 \%)$ \\
\hline & Female & \\
& Age distribution & $35(4.2 \%)$ \\
& $0-14$ & $164(19.6 \%)$ \\
2. & $15-29$ & $245(29.3 \%)$ \\
& $30-45$ & $224(26.8 \%)$ \\
& $46-60$ & $136(16.3 \%)$ \\
& $61-75$ & $32(3.8 \%)$ \\
\hline 3. & Above 75 & $284(34.0 \%)$ \\
& Occupation & $219(26.2 \%)$ \\
& Serving (defence) & $174(20.8 \%)$ \\
& Retiered & $159(21.2 \%)$ \\
\hline
\end{tabular}

Table 2: Clinical Profile of COVID 19 Patients

\begin{tabular}{|c|c|c|}
\hline S. no. & Characteristics & Number (Percentage) \\
\hline \multirow{2}{*}{1.} & Symptomatic & $667(79.8 \%)$ \\
& Yes & $169(20.2 \%)$ \\
\hline \multirow{2}{*}{2.} & No & $438(65.66 \%)$ \\
& With Fever & $229(34.33 \%)$ \\
\hline \multirow{2}{*}{3.} & without fever & $502(75.26 \%)$ \\
& Respiratory symptoms & $165(24.74 \%)$ \\
\hline & Present & $19(2.85 \%)$ \\
4. & Absent & $648(97.15 \%)$ \\
\hline \multirow{3}{*}{5.} & Anosmia/dyguesia/ dysosmia & $249(29.8 \%)$ \\
& Present & $587(70.2 \%)$ \\
\hline & Absent & $126(50.6 \%)$ \\
\hline. & Co-morbidities & $123(49.39 \%)$ \\
\hline
\end{tabular}

Table 3: Age-Wise and Sex-Wise Distribution of Death

\begin{tabular}{|c|c|c|}
\hline S.No & Characteristics & Deaths $(\mathbf{n}=33)$ \\
\hline $\mathbf{1}$ & Age in years & \\
& $0-14$ & 0 \\
& $15-29$ & 1 \\
& $30-45$ & 2 \\
& $46-60$ & 5 \\
& $61-75$ & 13 \\
& Above 75 & 12 \\
\hline $\mathbf{2}$ & Sex & 24 \\
& Male & 9 \\
\hline
\end{tabular}


NAYYAR ET AL.: A HOSPITAL BASED CROSS-SECTIONAL STUDY OF EPIDEMIOLOGICAL TREND OF COVID-19....

Table 4: Association of Co-Morbidities with Patient Outcome

\begin{tabular}{|c|c|c|c|c|}
\hline \multirow{2}{*}{ Co-morbidities } & \multicolumn{4}{|c|}{ Outcome } \\
\cline { 2 - 5 } & Death (\%) & Discharge (\%) & Admitted (\%) & Total (N) \\
\hline Present & 9.2 & 63.9 & 26.9 & 249 \\
\hline Absent & 1.2 & 57.8 & 40.5 & 587 \\
\hline Total & 33 & 498 & 305 & 836 \\
\hline
\end{tabular}

Table 5: Association of Co Morbidities with Symptoms

\begin{tabular}{|c|c|c|c|}
\hline \multirow{2}{*}{ Co-morbidities } & \multicolumn{3}{|c|}{ SYMPTOMS } \\
\cline { 2 - 4 } & Absent (\%) & Present (\%) & Total (N) \\
\hline Present & 12.0 & 88.0 & 249 \\
\hline Absent & 20.8 & 79.2 & 587 \\
\hline Total & 169 & 667 & 836 \\
\hline
\end{tabular}

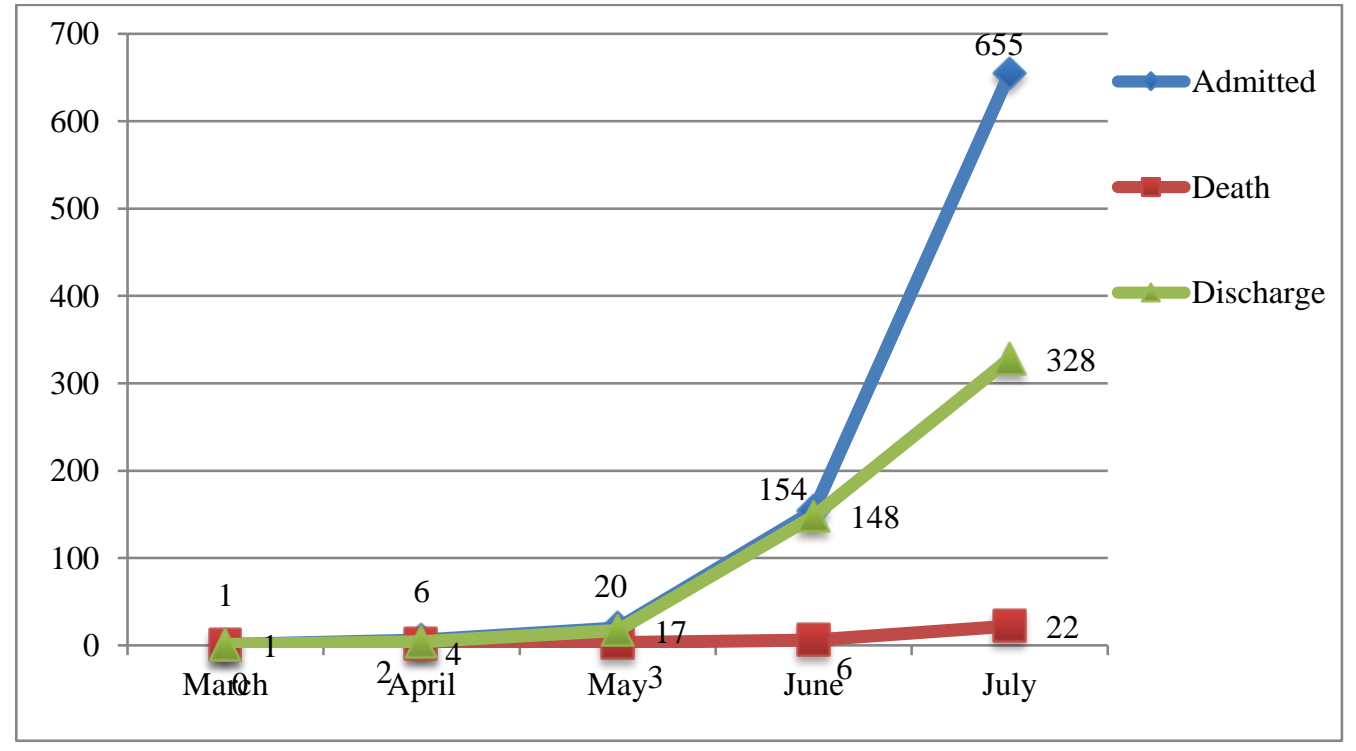

Figure 1: Month-Wise Trend of Admissions, Deaths and Discharge

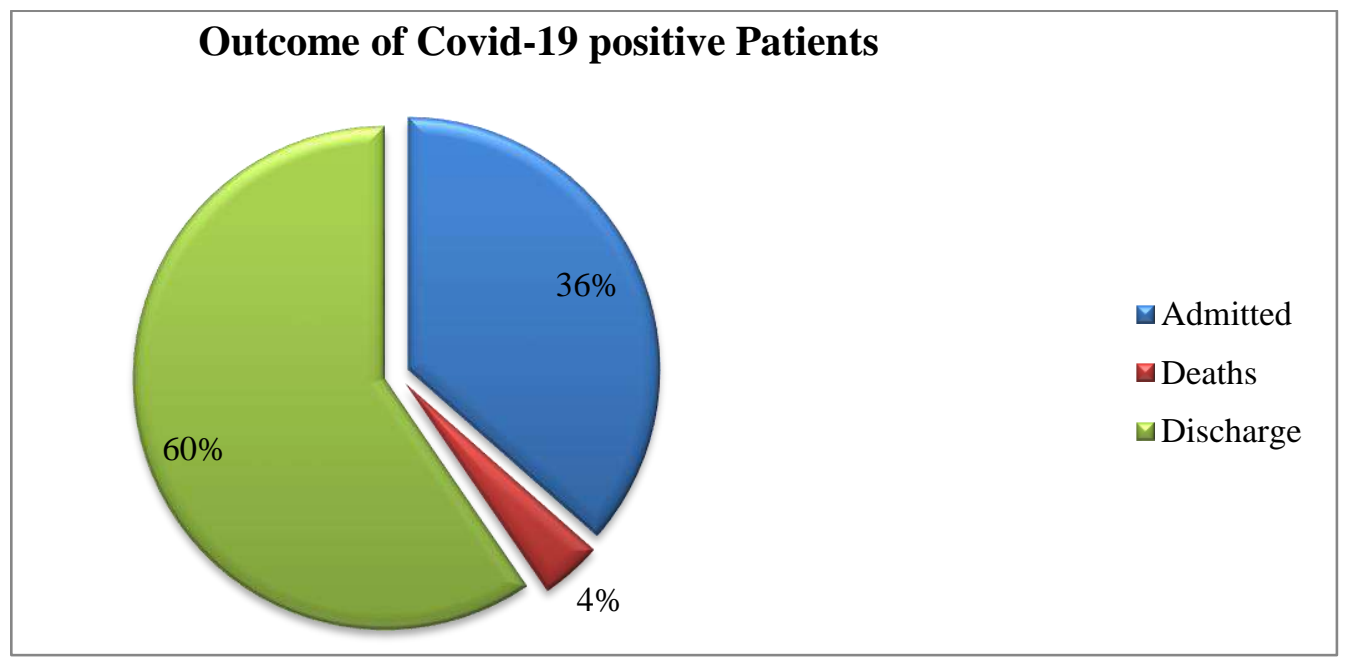

Figure 2: Outcome of Total Patients Admitted 


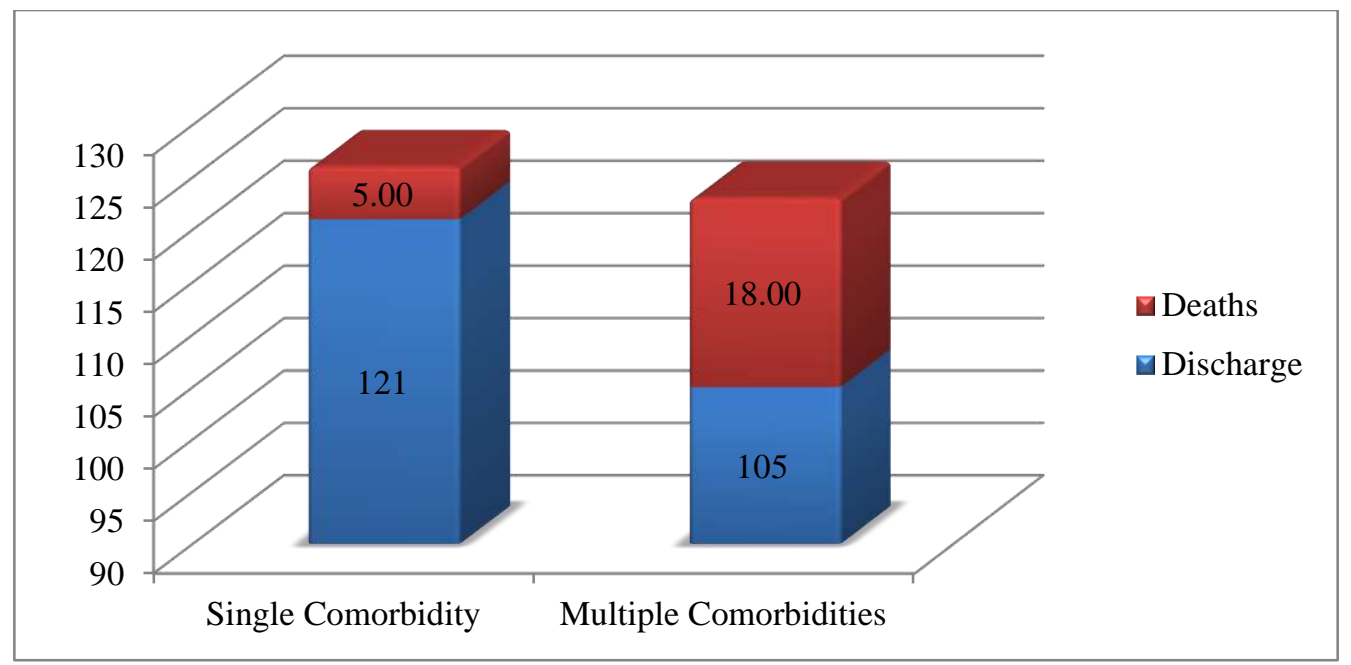

Figure 3: BI-Variate Analysis of Co-Morbidity and Outcome

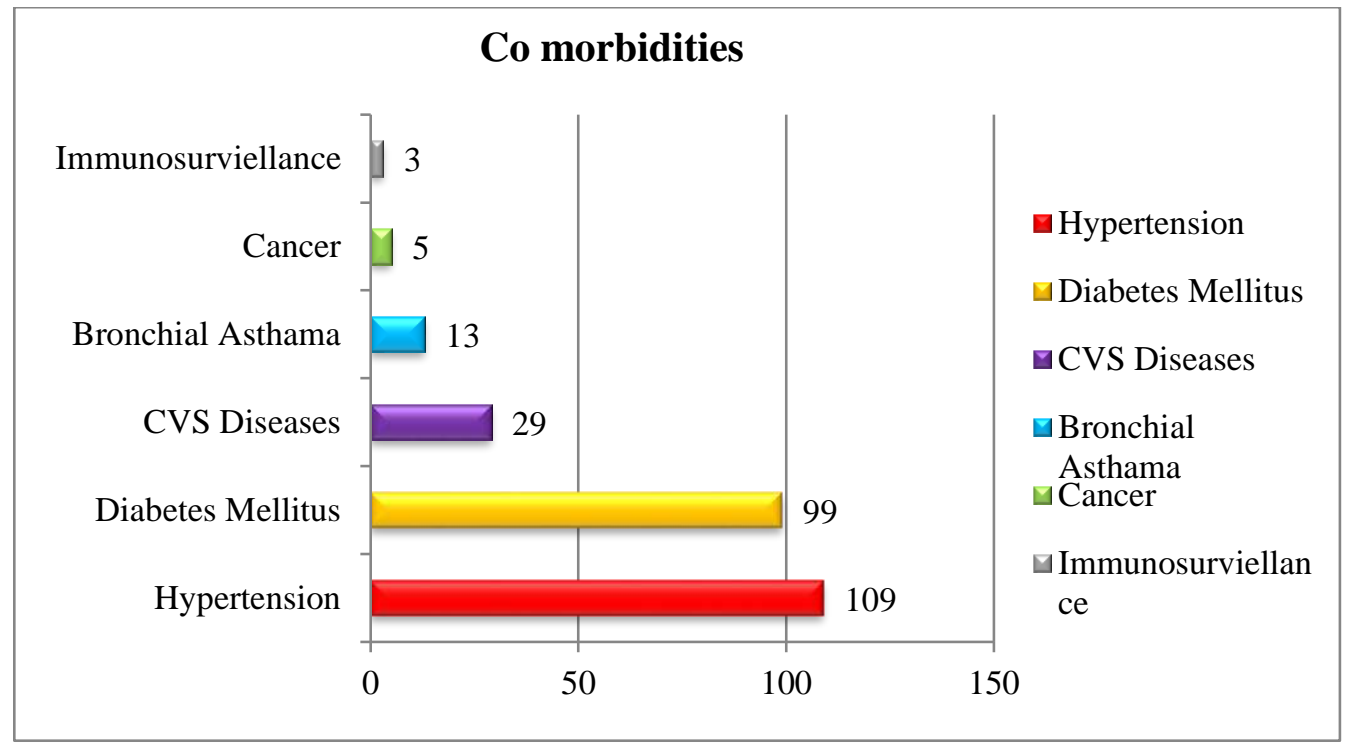

Figure 4: Most Common Co-Morbidities Found in Covid-19 Infected Patients

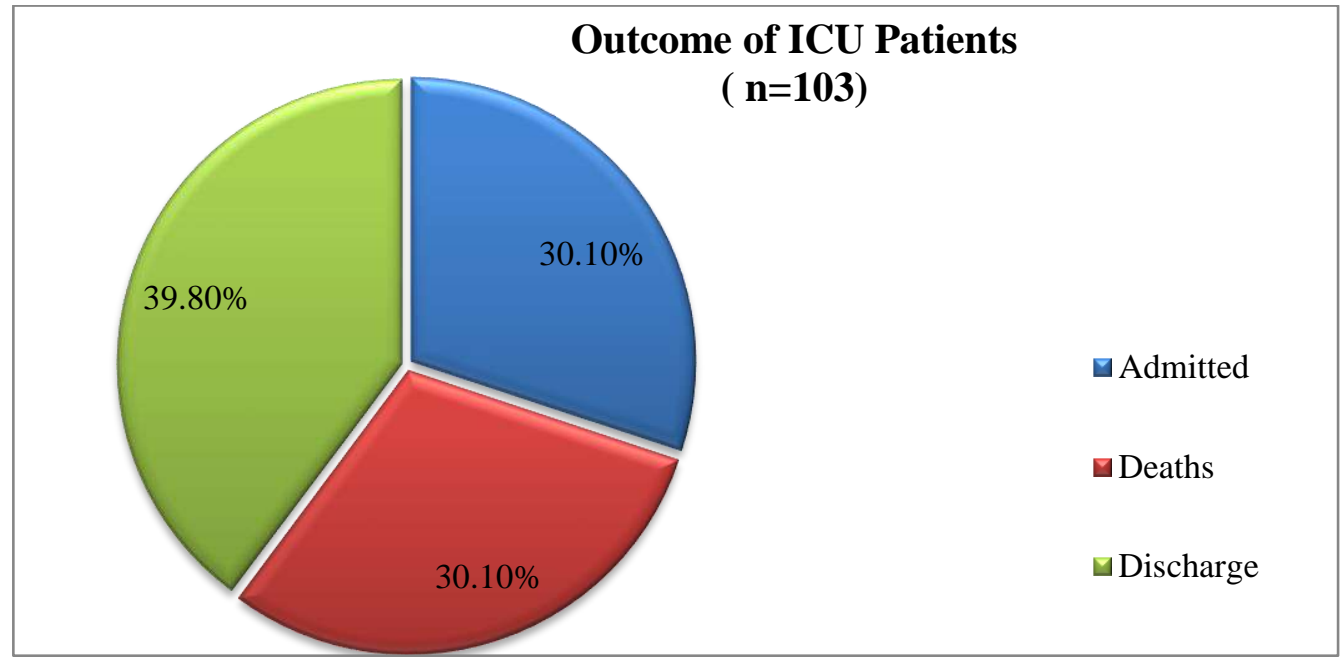

Figure 5: Outcome of ICU Patient 


\section{DISCUSSION}

In this epidemiological analysis, the prevalence of infection is more than double in males compare to that in females. These findings are similar to the study conducted by Gupta et al, where the percentage of males $(60 \%-70 \%)$ affected is more in comparison to females (30-40\%) (Gupta et al., 2020). In one of the studies in India conducted by Mahajan and Kaushal, (2020) 76\% cases are reported for men and $24 \%$ cases for women. In a contrast with other countries, women are found to be less positive for COVID-19 in India, while for early breakdown reports in China and Italy, the ratio is roughly equal for men and women (Livingston and Bucher, 2020) with an exception of South Korea where $60 \%$ women are found to be COVID-19 positive (Shi et al., 2020). The possible explanation could be more exposure, outdoor activities and travel in males as compared to females.

In our study, the median age of patients affected with Covid-19 is 43.94 years which is more in comparison to that reported throughout India, where median age is 39 years (Mahajan and Kaushal, 2020). However, median age recorded in our study is less to that of China and Italy which are 49.5 and 64 years respectively ((Livingston and Bucher, 2020; Shi et al., 2020). This represents the demographic variations between India and other countries. This might be due to the difference between the median age of an Indian which is expected to be 28.4 years and for China and Italy, it is expected to be 38.4 and 41.9 respectively in year 2020 (UN population report) (PDWP, 2019). The highest proportion of infection is observed in age group 30-45 years $(29.3 \%$ ), followed by age group 46-60 years (26.8\%). Very few cases have been reported in age group $0-14$ years $(4.2 \%)$ and above $75(3.8 \%)$. These findings correspond to the National figure of age group 30-45 years infected with Covid-19 (Gupta et al., 2020). The possible reason could be that middle age groups people are more prone for exposure due to involvement in outdoor activities and travel for work purpose.

Majority of patients were symptomatic with fever and other symptoms like (cough, sore throat etc $(52.4 \%)$ as chief complaints which is commonly seen in most of the viral illnesses followed by other symptoms like (cough, sore throat etc) but no fever (27.4\%) and rest asymptomatic (20\%). These findings correspond to the findings of similar study done by Gupta, 2020 where $68 \%$ patients were symptomatic and $32 \%$ were asymptomatic.

It has been well accepted that some comorbidities frequently coexist. For instance, diabetes and
COPD frequently coexist with hypertension or coronary heart diseases. Therefore, patients with multiple comorbidities are more likely to have poorer clinical outcomes (Guan et al., 2020). This study has verified the significant risk of poor prognosis in patients with two or more co-morbidities compared with those who had no or only single co morbidity. This spectrum of our report was largely consistent with existing literature in which the most prevalent co-morbidity was hypertension (16.9\%), followed by diabetes $(8.2 \%)$. Similarly in one of the other studies the most common co-morbidities identified were hypertension $(15.8 \%)$, cardiovascular and cerebrovascular conditions (11.7\%), and diabetes (9.4\%) (Paudel, 2002; Li et al., 2020). Therefore it is observed that patients with co-morbidities had greater disease severity and consequel compared with those without any co morbidity.

Majority of deaths $(39.3 \%)$ were seen between age group 61-75 yrs followed by age group 75-90 yrs (36\%) while no death was seen between age group 0-14 yrs. Similar findings are shown in study conducted by BJMC Pune that elderly adults have higher death rates of COVID-19 associated hospitalization (Tambe and Parande). One of the study also showed that $63 \%$ of all the deaths had occurred in those aged 60 years and older. The case-fatality rates in 3 age groups, namely, <40 years, 40 to 60 years, and $>60$ years were $0.40 \%, 2.36 \%$, and $8.89 \%$, respectively (Pal and Yadav, 2020).

The national trend shows CFR has been falling steadily and for the first time it dipped below $2.5 \%$. The case fatality rate of patients admitted with COVID-19 as on $31^{\text {st }} \mathrm{July}$ was $3.9 \%$ which is quite high as compared to the national average figure of $2.15 \%$ as on $31^{\text {st }} \mathrm{July}, 3.2 \%$ as on $8^{\text {th }}$ May and $3.38 \%$ as on Apr. The reason for that is Pune slowly emerged as the new major hotspot in Maharashtra and India.

\section{CONCLUSION}

Males were affected more in comparison to females. Median age of patients is 43.94 years which is more in comparison to that reported throughout India, where median age is 39 years. Majority of patients were symptomatic with fever and other symptoms like cough and sore throat $(52.4 \%)$ as chief complaints. Most common co-morbidities identified were hypertension, cardiovascular and cerebrovascular conditions and diabetes. Case fatality rate (CFR) of patients admitted with COVID-19 is quite high as compared to the national average figure. Death rate among patients with multiple comorbidities are quite high as compared to the patients admitted with single comorbidity. 


\section{LIMITATION OF THE STUDY}

This study is a cross-sectional study; however longitudinal study is required as more data over longer periods of time will allow for more concise and better results. Longitudinal study is effective in determining variable patterns over time.

The sample size in the current study is characterized by a small cohort. The more will be the sample size the better will be the results. Similarly, the larger the sample size the more information we have and so our uncertainty reduces. As our sample size increases, the confidence in our estimate increases, our uncertainty decreases and we have greater precision. Since this is a hospital based study, selection bias may occur.

\section{REFERENCES}

WHO Coronavirus Disease (COVID-19) Dashboard WHO Coronavirus Disease (COVID-19) Dashboard [Internet]. [cited 2020 Jul 25]. Available from: https://covid19.who.int/

Tomar A. and Gupta N., 2020. Prediction for the spread of COVID-19 in India and effectiveness of preventive measures. Sci. Total Environ [Internet]. 728: 138762. Available from: https://doi.org/10.1016/j.scitotenv.2020.138762

Raju N.V., 2020. Indian Publications on SARS-CoV-2: A Bibliometric Study of WHO COVID-19 Database. Med Rxiv., 2020.06.08.20125518.

MoHFW | Home [Internet]. [cited 2020 Jul 24]. Available from: https://www.mohfw.gov.in/

Available from: http://timesofindia.indiatimes.com/ articleshow/75364064.cms?utm_source=content ofinterest and utm_ medium=text and utm_campaign=cppst.

COVID 19 India portal dashboard [Internet] Available fromhttps://www.covid19india.org/state/MH

Gupta N., Agrawal S., Ish P., Mishra S., Gaind R. and Usha G., 2020. Clinical and epidemiologic profile of the initial COVID-19 patients at a tertiary care centre in India. Monaldi Arch Chest Dis., 901: 193-6. 10.4081/monaldi.2020.1294.

Gupta P.L., 2020. Epidemiological Analysis of Covid-19 Patients at a Dedicated Covid Hospital of Tertiary Care Centre. International Journal of Scientific Research, 9(8).
Guan W.-J., Liang W.-H. and Zhao Y., 2020. Comorbidity and its impact on 1590 patients with COVID-19 in China: a nationwide analysis. Eur. Respir J., 55: 2000547 [https://doi.org/10.1183/13993003.00547-2020].

Tambe and Parande, 2020. An Epidemiological Study of Laboratory Confirmed COVID-19 Cases Admitted in a Tertiary Care Hospital of Pune, Maharashtra.

Livingston E. and Bucher K., 2020. Coronavirus disease 2019 (COVID-19) in Italy. JAMA. doi: 10.1001/jama.2020.4344. [PubMed] [CrossRef] [Google Scholar]

Shi H., Han X., Jiang N., Cao Y., Alwalid O., Gu J., Fan Y. and Zheng C., 2020. Radiological findings from 81 patients with COVID-19 pneumonia in Wuhan, China: A descriptive study. The Lancet Infectious Diseases. doi: 10.1016/S14733099(20)30086-4). [PMC free article] [PubMed] [CrossRef] [Google Scholar]

Mahajan P. and Kaushal J., 2020. Epidemic Trend of COVID-19 Transmission in India During Lockdown-1 Phase [published online ahead of print, 2020 Jun 23]. J. Community Health, pp 110. doi:10.1007/s10900-020-00863-3.

Population Division World Prospects 2019. (2019). United Nations Department of Economics and Social Affairs, Population Division. Retrieved April 16, 2020 from https://population.un.org/wpp/Download/St andard/Population/ [Ref list]

Paudel S.S., 2020. A meta-analysis of 2019 novel coronavirus patient clinical characteristics and comorbidities. Research Square. 10.21203/rs.3.rs-21831/v1 [Accessed April 18, 2020, https://www.researchsquare.com/article/rs $-21831 / \mathrm{v} 1]$.

Li Q., Med M., Guan X., Wu P. and Wang X., 2020. Early transmission dynamics in Wuhan, China, of novel coronavirus-infected pneumonia. N. Engl. J. Med., 382: 1199-1207. doi: 10.1056/NEJMoa2001316. [PMC free article] [PubMed] [CrossRef] [Google Scholar]

Pal R. and Yadav U., 2020. COVID-19 Pandemic in India: Present Scenario and a Steep Climb Ahead. Journal of Primary Care \& Community Health. doi:10.1177/2150132720939402. 